\title{
Improvement of Pharmaceutical Properties of Zerumbone, a Multifunctional Compound, Using Cyclodextrin Derivatives
}

\author{
Md Mahadi Hassan, ${ }^{a, b}$ Ahmed Fouad Abdelwahab Mohammed, ${ }^{a, c, d}$ Khaled M. Elamin, ${ }^{e}$ \\ Hari Prasad Devkota, ${ }^{a, b}$ Yoshitaka Ohno, ${ }^{a, b}$ Keiichi Motoyama, ${ }^{a}$ Taishi Higashi, ${ }^{*, a, c}$ and \\ Teruko Imai $*, a, f$ \\ ${ }^{a}$ Graduate School of Pharmaceutical Sciences, Kumamoto University; 5-1 Oe-honmachi, Chuo-ku, Kumamoto 862 \\ 0973, Japan: ${ }^{b}$ Program for Leading Graduate Schools, Health Life Science: Interdisciplinary and Glocal Oriented \\ (HIGO) Program, Kumamoto University; 5-1 Oe-honmachi, Chuo-ku, Kumamoto 862-0973, Japan: ${ }^{c}$ Priority \\ Organization for Innovation and Excellence, Kumamoto University; 5-1 Oe-honmachi, Chuo-ku, Kumamoto 862- \\ 0973, Japan,: ${ }^{d}$ Faculty of Pharmacy, Department of Pharmaceutics, Minia University; Minia 61519, Egypt: ${ }^{e}$ Global \\ Center for Natural Resources Sciences, Faculty of Life Sciences, Kumamoto University; 5-1 Oe-honmachi, Chuo-ku, \\ Kumamoto 862-0973, Japan: and ${ }^{f}$ Daiichi University of Pharmacy; 22-1 Tamagawa-machi, Minami-ku, Fukuoka \\ 815-8511 Japan.
}

Received August 3, 2020; accepted August 21, 2020

Zerumbone is a multifunctional compound which shows various biological activities, such as antitumor activity, anti-inflammatory activity, antiulcer activity, etc. However, to use Zerumbone as functional foods or medicines, its pharmaceutical properties such as solubility should be improved. In the present study, we prepared its inclusion complexes with various cyclodextrin (CyD) derivatives, and evaluated their solubility, release profile of the drug and cytotoxic activity. Among $11 \mathrm{CyDs}$, sulfobutylether (SBE)- $\beta$-CyD showed the highest solubilizing effect for Zerumbone. Phase solubility diagrams of SBE- $\beta$-CyD/Zerumbone in $10 \%$ methanol solution showed $A_{L}$ type, and the stability constant was $756 \mathrm{M}^{-1}$. SBE- $\beta$-CyD also formed the solid complex with Zerumbone by kneading for $90 \mathrm{~min}$. Importantly, the dissolution rate of Zerumbone was improved by complexation with SBE- $\beta$ - and hydroxypropyl (HP)- $\beta$-CyDs, and its supersaturation was maintained for several hours. The solubilizing effects by SBE- $\beta$-CyD was greater than that of HP- $\beta$-CyD. Moreover, SBE- $\beta$-CyD/Zerumbone complex also retained the cytotoxic activity of Zerumbone. These results suggest that CyDs, especially SBE- $\beta$-CyD, were useful to improve the solubility of Zerumbone.

Key words cyclodextrin; Zerumbone; inclusion complex; supersaturation; solubilization

\section{Introduction}

Zerumbone (Fig. 1A) is a monocyclic sesquiterpenoid reported from the plants of Zingiberaceae family including Zingiber zerumbet Smith $^{1)}$ and Zingiber montanum (J. Koenig) Link ex A. Dietr. ${ }^{2)}$ In recent years, various studies have reported the potent biological activities of Zerumbone such as antioxidant, anti-inflammatory, anti-angiogenesis and antitumor activities. ${ }^{3)}$ However, the low water-solubility of Zerumbone is disadvantageous for the formulation design. Recently, Eid et $a .^{4)}$ reported inclusion complexation of Zerumbone by 2 -hydroxypropyl- $\beta$-cyclodextrin (HP- $\beta$-CyD) in both liquid and solid states; and the solubility of Zerumbone was improved $>30$ fold by the inclusion complexation with HP- $\beta$-CyD. In addition, the complex exhibited cytotoxic activity in human cancer cell lines. However, little is known about utilities of $\mathrm{CyD}$ derivatives except for HP- $\beta$-CyD for the improvement of pharmaceutical properties of Zerumbone.

In the present study, we have examined the improvement of solubility of Zerumbone by the complexation with various CyDs including parent and modified CyDs. Moreover, solid complexes of Zerumbone with CyDs were prepared by kneading method and characterized by differential scanning calorimetry (DSC) and powder X-ray diffraction. Furthermore, the dissolution behavior and cytotoxic activity of $\mathrm{CyD} /$ Zerumbone complexes were evaluated.

\section{Results and Discussion}

Figure 1B shows the solubility of Zerumbone in the presence of $10 \mathrm{mM}$ of various CyDs. In this study, $10 \%$ methanol aqueous solution was used as solvent because of extremely low water-solubility of Zerumbone. The solubility of Zerumbone in $10 \%$ methanol was approx. $0.9 \mathrm{mM}$, and was increased in the presence of CyDs; sulfobutylether (SBE) $\beta$-CyD $>$ dimethyl (DM)- $\beta$-CyD $>$ methyl (M) $\beta$-CyD $>$ HP- $\beta$-CyD $>$ maltosyl (G2)- $\beta$-CyD $>$ glucuronylglucosyl (GUG) $-\beta-\mathrm{CyD}>\beta-\mathrm{Cy}$ $\mathrm{D}>\gamma-\mathrm{CyD}>\mathrm{HP}-\gamma-\mathrm{CyD}>\mathrm{HP}-\alpha-\mathrm{CyD}>\alpha-\mathrm{CyD} . \quad$ Especially, SBE- $\beta$-CyD, M- $\beta$-CyD and DM- $\beta$-CyD showed remarkable solubilizing effect beyond HP- $\beta$-CyD. These results indicate that $\mathrm{SBE}-\beta-\mathrm{CyD}, \mathrm{M}-\beta-\mathrm{CyD}$ and $\mathrm{DM}-\beta-\mathrm{CyD}$ are useful to improve the solubility of Zerumbone. However, M- $\beta$-CyD and DM- $\beta$-CyD showed toxicity compared to HP- $\beta-\mathrm{CyD}$ and $\mathrm{SBE}-\beta-\mathrm{CyD}^{5)}$; therefore, we used SBE- $\beta-\mathrm{CyD}$ and $\mathrm{HP}-\beta-\mathrm{CyD}$ for following studies.

To examine the solubilizing effects of SBE- $\beta$-CyD and HP- $\beta$-CyD in detail, phase solubility diagrams of CyDs/ Zerumbone were determined (Fig. 1C). Both diagrams showed $\mathrm{A}_{\mathrm{L}}$ type, suggesting the $1: 1$ complex between $\mathrm{CyD}$ and Zerumbone. HP- $\beta$-CyD and SBE- $\beta$-CyD dissolved $8 \mathrm{mM}$ and $18 \mathrm{mM}$ Zerumbone at $50 \mathrm{mM}$, respectively, indicating higher solubilizing effect of SBE- $\beta-\mathrm{CyD}$ than HP- $\beta-\mathrm{CyD}$. Moreover, the stability constant $\left(K_{\mathrm{c}}\right)$ of $\mathrm{HP}-\beta-\mathrm{CyD} /$ Zerumbone and $\mathrm{SBE}-\beta-\mathrm{CyD} /$ Zerumbone were determined as $255 \mathrm{M}^{-1}$ and 
(A)

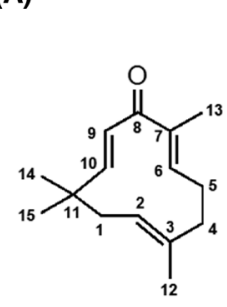

(B)

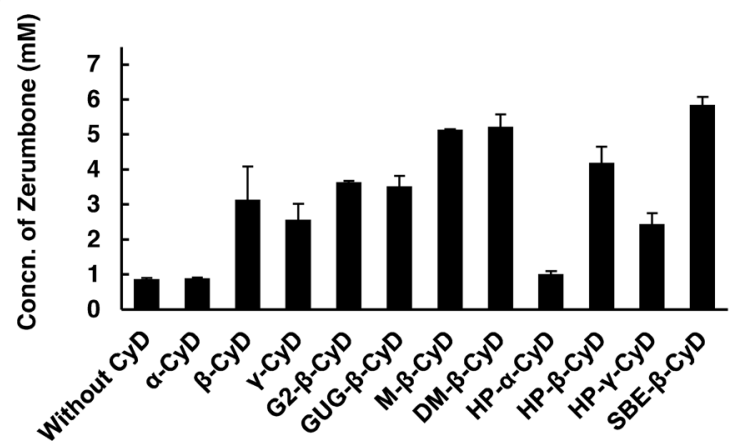

(C)

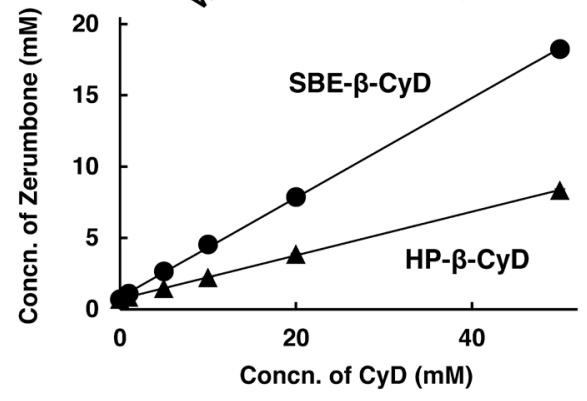

(D)

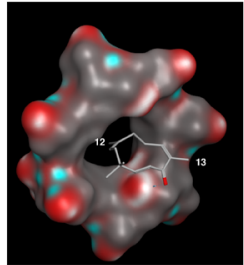

$+\beta-$ CyD

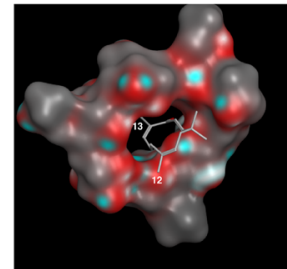

$+\mathrm{HP}-\beta-\mathrm{CyD}$

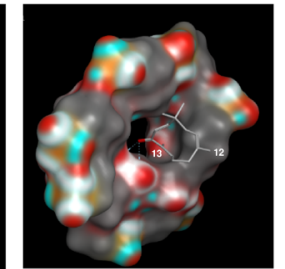

+ SBE- $\beta$-CyD

Fig. 1. (A) Structure of Zerumbone, (B) Solubility of Zerumbone in 10\% Methanol Including $10 \mathrm{mM}$ of Various CyDs, (C) Phase Solubility Diagrams of CyDs/Zerumbone and (D) Optimized Structures of CyDs/Zerumbone Complexes

Gray compound and broken lines represent Zerumbone and hydrogen bonds, respectively. (B, C) Each value represents the mean \pm standard error (S.E.) of 3 experiments. (Color figure can be accessed in the online version.)

$756 \mathrm{M}^{-1}$, respectively. These results suggest that $\mathrm{SBE}-\beta-\mathrm{CyD}$ improves the solubility of Zerumbone compared to HP- $\beta$-CyD.

To estimate the interaction modes and complexation binding energies of CyDs/Zerumbone, a molecular operating environment software (MOE, version 2018) was employed according to the Geng's method. ${ }^{6)}$ SBE- $\beta$-CyD and HP- $\beta$-CyD interacted with the parts around 13-position of methyl group of Zerumbone, whereas $\beta$-CyD did with the parts around 12-position of methyl group (Fig. 1D). Moreover, binding energy of SBE- $\beta$-CyD/Zerumbone $(-18.72 \mathrm{kcal} / \mathrm{mol})$ was lower than that of HP- $\beta$-CyD/Zerumbone $(-16.24 \mathrm{kcal} / \mathrm{mol})$ or $\beta-\mathrm{CyD} /$ Zerumbone $(-13.66 \mathrm{kcal} / \mathrm{mol})$, indicating that $\mathrm{SBE}-\beta-\mathrm{CyD}$ strongly interacts with Zerumbone compared to HP- $\beta$-CyD.

To characterize kneading products of CyDs/Zerumbone, DSC was measured (Fig. 2A). Zerumbone showed endothermic peak at $66.7^{\circ} \mathrm{C}$ (Fig. 2a), as same as physical mixtures of CyDs/Zerumbone (Figs. 2b, c). In contrast, the peak was almost disappeared in the kneading products of $\mathrm{HP}-\beta-\mathrm{CyD} /$ Zerumbone (Fig. 2d) and SBE- $\beta$-CyD/Zerumbone (Fig. 2e), suggesting a breakdown of the crystal lattice of Zerumbone by its complexation with CyDs.

To make sure the complexation between CyDs and Zerumbone in the solid state, powder X-ray diffraction was measured (Fig. 2B). The Zerumbone (Fig. 2f) and physical mixtures of CyDs/Zerumbone (Figs. 2g, h) showed the peaks derived
(A) DSC

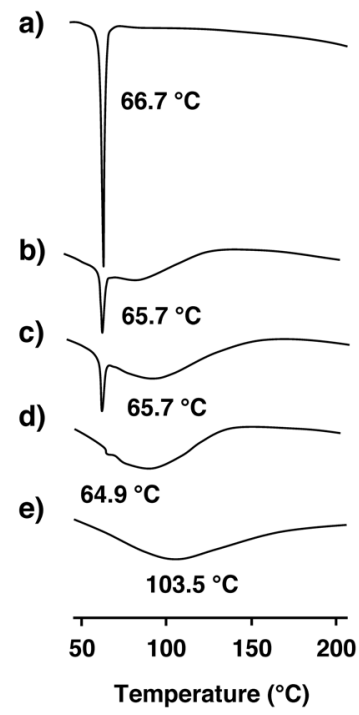

(B) Powder X-ray diffraction

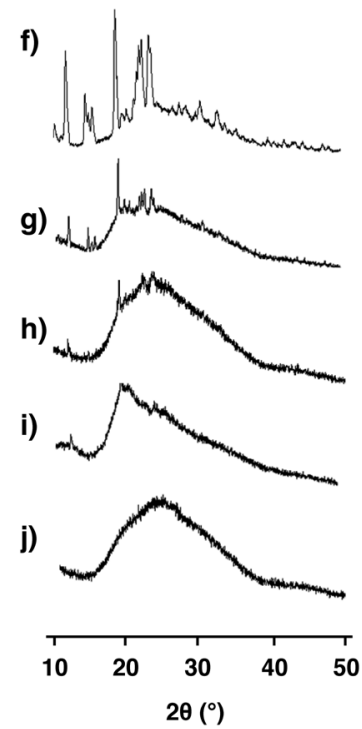

Fig. 2. (A) DSC and (B) Powder X-Ray Diffraction of $(a, f)$ Zerumbone, Physical Mixtures of (b, g) HP- $\beta$-CyD/Zerumbone or (c, h) SBE- $\beta$-CyD/ Zerumbone, and Kneading Products of (d, i) HP- $\beta$-CyD/Zerumbone or (e, j) $\mathrm{SBE}-\beta$-CyD/Zerumbone 
from its crystal structure. On the other hand, the peaks were disappeared in kneading products of $\mathrm{HP}-\beta-\mathrm{CyD} /$ Zerumbone (Fig. 2i) and SBE- $\beta$-CyD/Zerumbone (Fig. $2 \mathrm{j}$ ), suggesting the dispersion of Zerumbone in a monomolecular state in kneading products. These results suggest that Zerumbone forms inclusion complexes with SBE- $\beta$-CyD and HP- $\beta$-CyD in the solid state.

We next performed dissolution test using the kneading products containing $1.98 \mathrm{mg}$ of Zerumbone in $10 \mathrm{~mL}$ of phosphate buffered saline (PBS, $\mathrm{pH} 7.4$ ) at $37^{\circ} \mathrm{C}$, an experimental condition in which insoluble particles are presence (Fig. 3). The release rate of Zerumbone from the kneading product with SBE- $\beta$-CyD dramatically increased at $3 \mathrm{~h}$ when compared to that of the physical mixture which dissolved and reached equilibrium of Zerumbone in $0.9 \mathrm{mM} \mathrm{CyD}$ solution, and was higher than that of the kneading product with HP- $\beta$-CyD. Interestingly, the release rate of both kneading products decreased after $3 \mathrm{~h}$, suggesting the supersaturation state of Zerumbone. In this connection, the dissolution of Zerumbone from the kneading products of $\mathrm{HP}-\beta-\mathrm{CyD}$ and $\mathrm{SBE}-\beta-\mathrm{CyD}$ was slightly decreased compared to the corresponding physi-

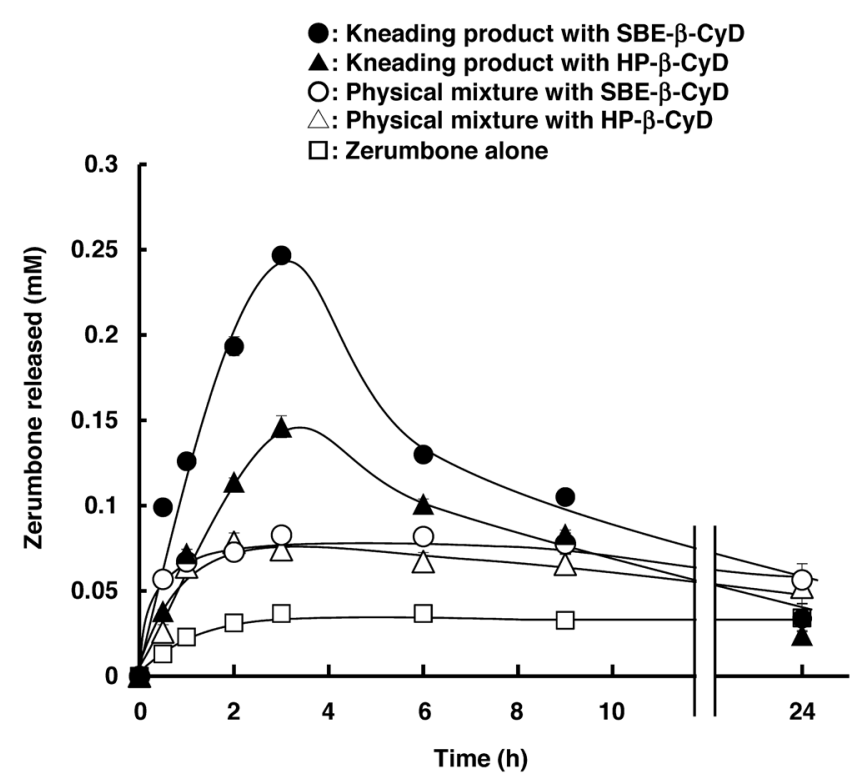

Fig. 3. Release of Zerumbone from the Solid Complexes with SBE- $\beta$-CyD and HP- $\beta$-CyD

Each value represents the mean \pm S.E. of 3 experiments. cal mixtures at $24 \mathrm{~h}$. This is probably within error margin because of measurement accuracy. Anyhow, these results suggest that $\mathrm{CyD}$ derivatives are useful to maintain the supersaturation state of Zerumbone. The supersaturating drug delivery systems have been acknowledged as a promising concept to obtain adequate oral bioavailability. ${ }^{7)}$ Therefore, the results indicate the great potential of SBE- $\beta-\mathrm{CyD}$ as a solubilizing agent for Zerumbone.

Zerumbone shows cytotoxic activity after its cellular uptake and subsequent induction of apoptosis. In general, CyD complex is negligibly taken into the cells because of its high hydrophilicity and high-molecular weight; thus, to confirm the activity of $\mathrm{CyD} /$ Zerumbone complexes is essential. Therefore, we next evaluated cytotoxic activities of $\mathrm{CyD} /$ Zerumbone complexes in $\mathrm{KB}$ cells (Fig. 4). In this study, to assure the soluble condition of the complexes, $0.75-1.5 \%$ dimethyl sulfoxide (DMSO) was added in the samples, and preliminary confirmed the negligible cytotoxic activity of DMSO alone (data not shown). Zerumbone complexes with SBE- $\beta$-CyD and HP- $\beta$-CyD showed cytotoxic activities, and were equivalent to that of Zerumbone alone. Thus, the cytotoxic activities of Zerumbone in the complexes with SBE- $\beta$-CyD and HP- $\beta$-CyD were retained in KB cells. As future efforts, we should examine the in vivo antitumor activity of $\mathrm{CyD} /$ Zerumbone complexes.

\section{Conclusion}

In this study, we evaluated various $\mathrm{CyD}$ derivatives as solubilizing agents for Zerumbone, and demonstrated that SBE- $\beta$-CyD shows the most potent solubilizing effect and sustainability of supersaturation state for Zerumbone. SBE- $\beta$-CyD formed inclusion complex with Zerumbone in both solid and liquid states, and cytotoxic activity of Zerumbone in the complex with SBE- $\beta$-CyD was completely retained in $\mathrm{KB}$ cells. These results suggest the potential of SBE- $\beta$-CyD as a promising pharmaceutical material for Zerumbone.

\section{Experimental}

Materials and Methods Zerumbone was isolated from the dried rhizomes of Zingiber montanum (J. Koenig) Link ex A. Dietr as previously described. ${ }^{2)} \alpha-\mathrm{CyD}, \beta$-CyD, $\gamma$-CyD and HP-CyDs in which hydroxypropyl groups were mainly grafted at 2-position of secondary hydroxy groups (degree of substitution: DS 4.4) were supplied by Nihon Shokuhin Kako Co., Ltd. (Tokyo, Japan). SBE- $\beta$-CyD (DS 6.2-6.9) was sup-

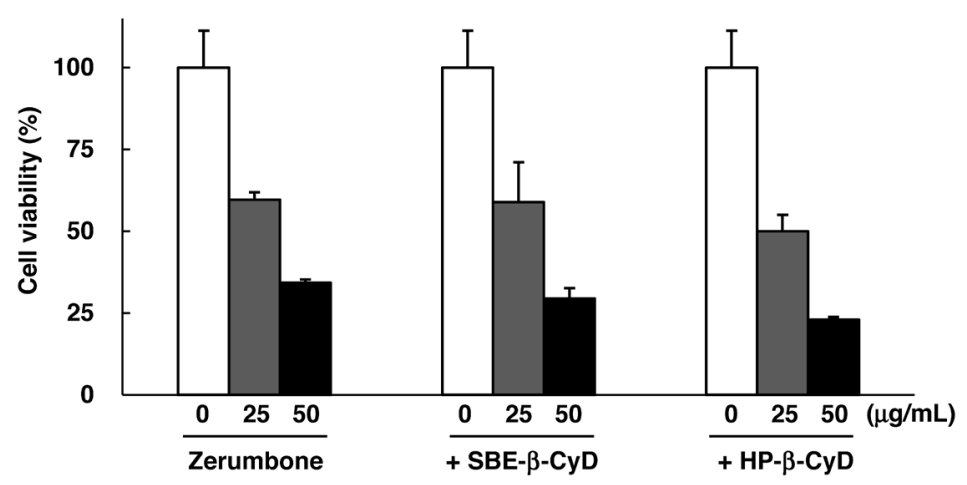

Fig. 4. Cytotoxic Activity of Zerumbone Complexes with SBE- $\beta$-CyD and HP- $\beta$-CyD

Each value represents the mean \pm S.E. of 3 experiments. 
plied by CyDing Co., Ltd. (Kumamoto, Japan). G2- $\beta$-CyD and GUG- $\beta$-CyD were supplied by Ensuiko Sugar Refining (Tokyo, Japan). M- $\beta$-CyD (DS 12.2) and DM- $\beta$-CyD (DS 14.0) were purchased from Tokyo Kasei (Tokyo, Japan) and Wako Pure Chemical Corporation (Osaka, Japan), respectively.

Solubility Studies An excess amount of Zerumbone ( $5 \mathrm{mg}$ ) was added to $1 \mathrm{~mL}$ of $10 \%$ methanol aqueous solution containing various concentration of CyDs $(0-50 \mathrm{mM})$. Then the solutions were shaken at $25^{\circ} \mathrm{C}$ for $24 \mathrm{~h}$. After filtration of each solution by syringe filter $(0.2 \mu \mathrm{m}$, Advantec, Tokyo, Japan), the concentration of dissolved Zerumbone was determined by absorbance at $242 \mathrm{~nm}$ by using Spectrophotometer (JASCO V-650 UV-visible Spectrophotometer, Tokyo, Japan). The solubility of Zerumbone was plotted to CyD concentrations, and $K_{\mathrm{c}}$ was calculated using the slope and intercept according to the following equation.

$$
K_{\mathrm{c}}=\text { slope } / S_{0}(1-\text { slope })
$$

Where, intercept represents $S_{0}$, the intrinsic solubility of Zerumbone in $10 \%$ methanol.

Molecular Operating Environment (MOE) Simulation The 3D structure of $\beta$-CyD was extracted by MOE from the protein data bank (PDB ID: $1 \mathrm{Z0N}$ ). Then, HP- $\beta$-CyD and SBE- $\beta$-CyD were constructed by the incorporation of 2-hydroxypropyl groups and sulfobutylether groups at 2-position of secondary hydroxy groups and 6-position of primary hydroxy groups of $\beta$-CyD, respectively, using ChemDraw professional version 16.0.1.4 (61) molecular builder. To estimate interaction modes and binding energies of CyDs/Zerumbone, MOE was performed as reported previously. ${ }^{6)}$

Preparation of Kneading Product or Physical Mixture To obtain the kneading product, the powder of HP- $\beta$-CyD $(0.3473 \mathrm{~g})$ or SBE- $\beta$-CyD $(0.5425 \mathrm{~g})$ was mixed with Zerumbone $(0.0545 \mathrm{~g})$ at a molar ratio $1: 1$, and was kneaded for $90 \mathrm{~min}$ with appropriate volume of water during the kneading process. Then, the samples were dried under the reduced pressure for $24 \mathrm{~h}$. To obtain the physical mixture, the same amounts of powders of Zerumbone and CyDs were mixed using a mortar and pestle for $5 \mathrm{~min}$.

Differential Scanning Calorimetry (DSC) In measurement of DSC (AutoQ20, TA Instruments, Tokyo, Japan), the solid samples (approx. $3 \mathrm{mg}$ ) were placed in a flat-bottomed aluminum pan, heated at $10^{\circ} \mathrm{C} / \mathrm{min}$ and scanned at $0-300^{\circ} \mathrm{C}$ under a constant flow of dry nitrogen.

Powder X-Ray Diffraction Powder X-ray diffraction patterns were measured by Rigaku Ultima IV X-ray diffractom- eter (Tokyo, Japan). The voltage was $40 \mathrm{kV}$ and $30 \mathrm{~mA}$. The scanning rate was $2 \%$ min at $5-50^{\circ}$.

Release Profile The solid samples including $1.98 \mathrm{mg}$ of Zerumbone were added in $10 \mathrm{~mL}$ of PBS (pH 7.4) at $37^{\circ} \mathrm{C}$. At appropriate intervals, $1 \mathrm{~mL}$ of the medium was collected and filtered $(0.2 \mu \mathrm{m}$, DISMIC-25 CS, Toyo Roshi, Tokyo, Japan). The fresh $1 \mathrm{~mL}$ of PBS was added in the medium to adjust the total volume to $10 \mathrm{~mL}$. The concentration of Zerumbone in the filtrate was determined by absorbance at $242 \mathrm{~nm}$.

Cytotoxic Activity KB cells were obtained from the Institute of Development, Aging and Cancer (IDAC), Tohoku University (Sendai, Japan). The cells were grown in RPMI-1640 culture medium containing penicillin $\left(1 \times 10^{5} \mathrm{mU} / \mathrm{mL}\right)$ and streptomycin $(0.1 \mathrm{mg} / \mathrm{mL})$ supplemented with $10 \%$ fetal bovine serum (FBS) at $37^{\circ} \mathrm{C}$ in a humidified $5 \% \mathrm{CO}_{2}$ and $95 \%$ air atmosphere. $\mathrm{KB}$ cells were seeded in 96 well plate at $\left(2 \times 10^{4}\right.$ cell/well $)$ and incubated for $24 \mathrm{~h}$. Cells were treated with 0.75 and $1.5 \%$ DMSO solutions containing 25 and $50 \mu \mathrm{g} / \mathrm{mL}$ of Zerumbone and CyDs at a molar ratio $1: 1$, respectively. After the incubation at $37^{\circ} \mathrm{C}$ for $36 \mathrm{~h}$, cell viability was determined by the WST-1 method (Wako Pure Chemical Corporation, Osaka, Japan). WST-1 formazan was monitored by microplate reader Multiskan FC (Thermo Scientific, Waltham, MA, U.S.A.).

Acknowledgments This work was partially supported by Program for Leading Graduate Schools "HIGO (Health life science: Interdisciplinary and Glocal Oriented) Program,” Kumamoto University.

Conflict of Interest Dr. Motoyama and Dr. Higashi are technical advisors of CyDing Co., Ltd. (Kumamoto, Japan).

\section{References}

1) Dev S., Tetrahedron, 8, 171-180 (1960).

2) Hassan M. M., Adhikari-Devkota A., Imai T., Devkota H. P., Separations, 6, 31 (2019).

3) Kalantari K., Moniri M., Moghaddam B. A., Abdul Rahim R., Ariff B. A., Izadiyan Z., Mohamad R., Molecules, 22, 1645 (2017).

4) Eid E. E. M., Abdul A. B., Suliman F. E. O., Sukari M. A., Rasedee A., Fatah S. S., Carbohydr. Polym., 83, 1707-1714 (2011).

5) Irie T., Uekama K., J. Pharm. Sci., 86, 147-162 (1997).

6) Geng Q., Li T., Wang X., Chu W., Cai M., Xie J., Ni H., Sci. Rep., 9. $1882(2019)$

7) Brouwers J., Brewster M. E., Augustijns P., J. Pharm. Sci., 98, 2549-2572 (2009). 